\title{
NOVA ROTA DA SEDA: CHINA E SUA MAXIMIZAÇÃO ECONÔMICA POR RECURSOS DE PODER
}

Bruna Leal Barcellos ${ }^{1}$ Leonardo Mèrcher ${ }^{2}$

Resumo: O presente artigo busca investigar a Nova Rota da Seda enquanto ferramenta de maximização de recursos de poder pela China junto ao cenário internacional. A presente pesquisa aplica conceitos do realismo ofensivo de Mearshemier e cruza dados quantitativos com a análise qualitativa das práticas chinesas nos países afetados pela Nova Rota da Seda. Com objetivo de apresentar o crescimento econômico como fator de crescimento de recursos de poder, os principais resultados obtidos apontam para: i. uma real corrida chinesa por garantir e maximizar recursos de poder; ii. advinda de uma diversificação e menor dependência das potências estabelecidas em sua balança comercial; iii. que resultaria em conflitos econômicos e de segurança com essas potências, reforçando o ciclo de diversificação.

Palavras-chave: China. Nova Rota da Seda. Realismo ofensivo.

\section{NEW SILK ROAD: CHINA AND ITS ECONOMIC MAXIMIZATION THROUGH POWER RESOURCES}

Abstract: This paper aims to investigate the New Silk Road as a Chinese tool for maximizing its power resources on the international stage. This research applies concepts from Mearshemier's offensive realism and crosses quantitative data with the qualitative analysis of Chinese practices in the countries affected by the New Silk Road. In order to present economic growth as a growth factor for power resources, the main results obtained in this research point to: i. a real Chinese race to secure and maximize power resources; ii. arising from diversification and less dependence on the powers established in its trade balance; iii. which would result in economic and security conflicts with these powers, reinforcing the diversification cycle.

Keywords: China. New Silk Road. Offensive realism.

\section{NUEVA RUTA DE LA SEDA: CHINA Y SU MAXIMIZACIÓN ECONÓMICA MEDIANTE RECURSOS DE PODER}

Resumen: Este artículo busca investigar la Nueva Ruta de la Seda como una herramienta para maximizar los recursos energéticos de China en el escenario internacional. Esta investigación aplica conceptos del realismo ofensivo de Mearshemier y cruza datos cuantitativos con el análisis cualitativo de las prácticas chinas en los países afectados por la Nueva Ruta de la Seda. Para presentar el crecimiento económico como factor de crecimiento de los recursos energéticos, los principales resultados obtenidos apuntan a: i. una verdadera carrera china para asegurar y maximizar los recursos energéticos; ii. derivado de la diversificación y menor dependencia de los poderes establecidos en su balanza comercial; iii. lo que

\footnotetext{
1 Universidade Federal do Paraná, Curitiba, Brasil, brunalbarcellos@gmail.com, https://orcid.org/00000002-4386-4322

2 Universidade Federal do Paraná, Curitiba, Brasil, leomercher@gmail.com, https://orcid.org/0000$0003-1812-7803$
} 
daría lugar a conflictos económicos y de seguridad con estos poderes, reforzando el ciclo de diversificación.

Palabras clave: China. Nueva Ruta de la Seda. Realismo ofensivo.

\section{Introdução}

Exposta ao mundo em 2013, pelo presidente chinês Xi Jinping, a Nova Rota da Seda é uma proposta ambiciosa que busca firmar parcerias e construir novos caminhos logísticos para as trocas comerciais da China com a África e Eurásia. Para pesquisadores como Xinhua (2015), a iniciativa de uma Nova Rota da Seda (Figura 1) pode ser observada como uma extensão do próprio desenvolvimento nacional chinês que refletiria a percepção do governo em alcançar maior abertura comercial e de desenvolvimento. Contudo, restam dúvidas se a criação da Nova Rota da Seda seria apenas uma iniciativa comercial e que não se associaria com uma escalada de poder junto às potências internacionais.

Figura 1 - A Nova Rota da Seda: por terra e por mar

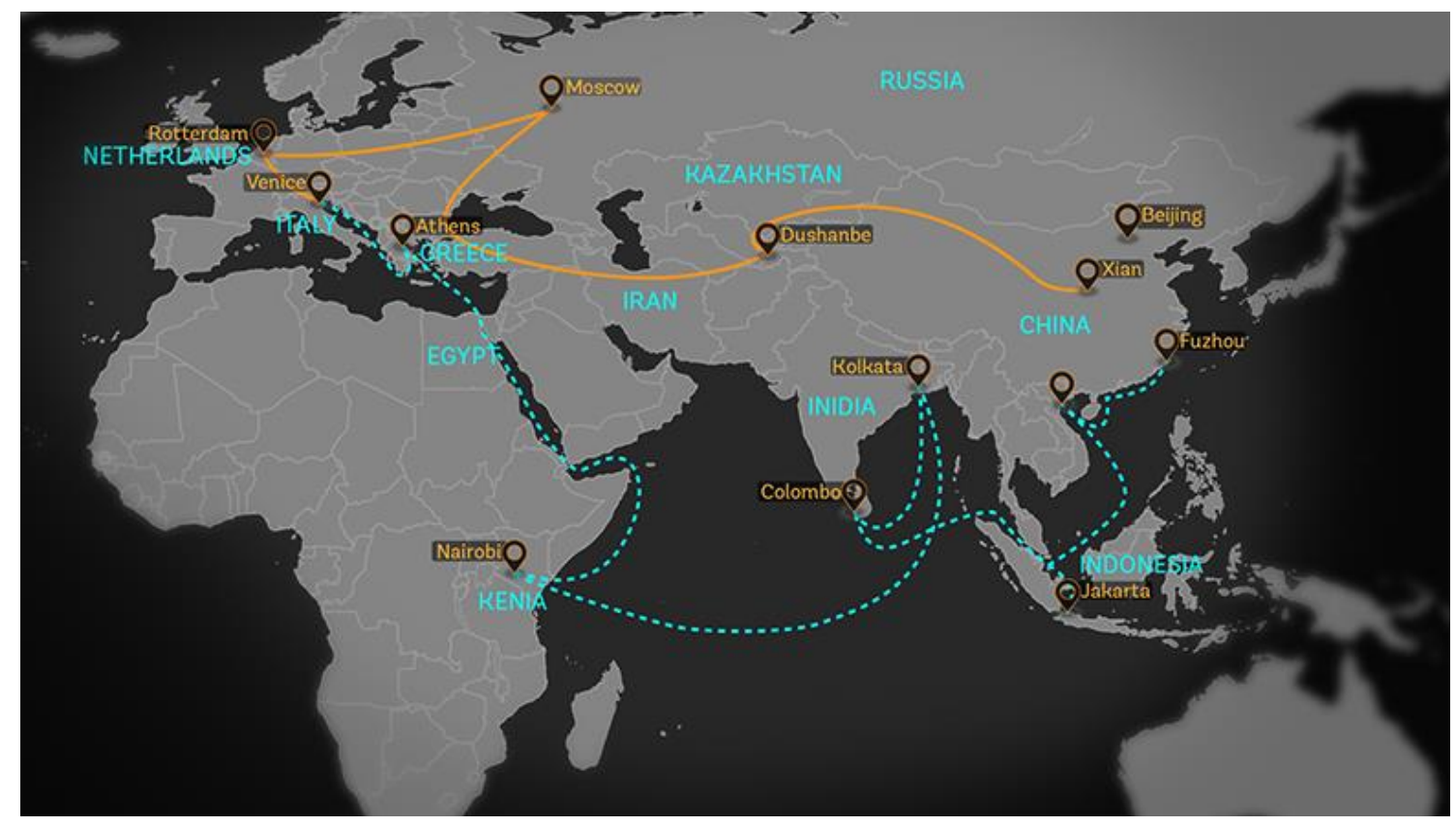

Fonte: COLAKOĞLU. Middle East Institute, 2019. Disponível em: < $<$ https://www.mei.edu/publications/chinas-belt-and-road-initiative-and-turkeys-middle-corridorquestion-compatibility> Acesso em: 15 de agosto de 2020.

As duas rotas comerciais e de infraestrutura que passa a receber investimentos chineses estariam no mar (transporte marítimo) e por terra (transporte terrestre e aéreo). Por mar teríamos seu início na China, passado estrategicamente pelos portos da Indonésia, Índia, Sri Lanka, Quênia, Egito e União Europeia, expandindo eventualmente pelo Vietnã, Malásia, lêmen e Omã, Arábia Saudita e Turquia. Por terra ou ar iniciaria na China, passando pelo Tajiquistão, Rússia e 
União Europeia, expandindo eventualmente pelo Oriente Médio (COLAKOĞLU. Middle East Institute, 2019). Ainda é pública manifestações do governo chinês a Nova Rota da Seda pode se expandir para outras nações africanas e até americanas, de acordo com os interesses de cooperação e liberação comercial.

Porém, para além de reproduzirmos aqui discursos governamentais, o presente artigo busca coletar dados sobre o comércio chinês e suas iniciativas concretas junto aos seus principais parceiros sob a ótica do realismo ofensivo de Mearsheimer (2001). Isso se dá por haver espaço para questionamentos quanto às intenções chinesas junto à estrutura internacional de poder. Por mais que a China rejeite em seu discurso a ideia de hegemonia, como veremos o longo da pesquisa, e nem esteja em uma posição hegemônica sobre as demais potências, ela mantém dados concretos de crescimento bélico, tecnológico e econômico que se associam ao conceito de maximização de poder de Mearscheimer (2001).

Dessa forma, o presente artigo, para além da presente introdução, inicia-se com uma seção breve de contextualização histórica da China em sua abertura à economia mundial no século XX até os dias atuais. Posteriormente analisa-se a balança comercial chinesa e são expostos os dados das importações totais dos últimos anos para identificarmos as mercadorias e suas origens, dando maior ênfase na divisão de dois grupos: as nações desenvolvidas e as em desenvolvimento, sendo esse último importante por expor os recursos (insumos) que alimentam o crescimento econômico chinês. Em um terceiro momento aplicamos os conceitos teóricos do realismo ofensivo para interpretarmos os dados da Nova Rota da Seda e responder se a China assumiu uma estratégia de ascender enquanto potência hegemônica nas relações internacionais - mesmo que seu discurso governamental não aponte para esse caminho. Em seguida estão os apontamentos de nossas considerações finais sobre a Nova Rota da Seda.

\section{China e sua expansão econômica}

Para que o leitor possa compreender como a China associou a economia à ação política internacional é preciso voltarmos, ainda que brevemente, nas reformas internas do país na segunda metade do século XX. Com a morte de Mao (1976) e a ascensão de Deng Xiaoping (1978-1992) inicia-se um novo momento na história chinesa (BARNETT, CLOUGH, 1986). O país que, até então, buscava o desenvolvimento de sua nação sem se apoiar tanto na economia de mercado, passou por uma transformação no fim dos anos 1970 e ao longo dos anos 1980. 
Sob o comando de Mao, a China não observava com bons olhos tópicos como abertura ao setor privado, a considerando uma atividade presente no capitalismo que não viria a contribuir ao sistema político e econômico chinês. No entanto, o crescimento populacional e a necessidade de desenvolvimento autossuficiente na China encontravam barreiras em relação à obtenção de matérias primas.

Unido a essa necessidade, o modelo de indústria stalinista e as dinâmicas de controle e recolhimento da produção de grãos (FAIRBANK, 2006; PUTTERMAN, 1992), praticados durante a liderança de Mao, não estavam mais apresentando os resultados esperados. Eventos de escassez, como a Grande Fome Chinesa (19581961), já haviam iniciado um processo de questionamento nacional sobre os rumos do país, encontrando solo político fértil na administração de Deng Xiaoping (19781992). A China, sob o comando de Deng, dava voz aos anseios de grupos internos que viam na abertura de mercado uma forma possível de, não só adquirir a mão de obra e alimento necessários, mas também de dar força à suas exportações e aumentar a arrecadação de capital estrangeiro para o financiamento doméstico.

As reformas que ocorreram gradativamente a partir de 1978 foram alterando a relação entre o Estado e o mercado, marcando uma política mais flexível. Muitas estatais chinesas (SOEs) foram unidas em grupos ou privatizadas, as cotas de preço existentes para a agricultura foram diminuídas até serem completamente eliminadas e o avanço da dinâmica de mercado ganhou força no país (ZHAO, ZHANG, 1999; CHEN, 2002). Outro importante aspecto desse momento de mudanças foi a criação das zonas econômicas a partir de 1980. A princípio quatro zonas econômicas especiais foram criadas, sendo elas “(...) em Shenzen, Zhuhai, Shantou e Xiamen (...)" (NONNENBERG, 2010, p. 204), auxiliando no processo de recepção de investimentos estrangeiros diretos (IEDs) (SACHS, 1994, p. 114) ao atraírem marcas estrangeiras para produzirem e exportarem seus produtos por mãos e portos chineses para o resto do mundo.

Essas mudanças criaram uma estrutura industrial competitiva mundialmente para exportação, ao mesmo tempo que aumentava a capacidade financeira e econômica da China para sustentar seu crescimento doméstico. Em 1968, década anterior as medidas implementadas, o PIB chinês era o de 70.85 bilhões de dólares. No mesmo ano, segundo o Banco Mundial (2020), os Estados Unidos teriam um PIB de 942.5 bilhões de dólares, e o Japão, 146,6 bilhões de dólares. Em 1988, o PIB chinês alcançou a marca de 312.35 bilhões de dólares, e até o último levantamento 
em 2018, o mesmo apresentava um total de 13.61 trilhões de dólares enquanto que o PIB dos Estados Unidos apresentava um total de 20,54 trilhões de dólares e o japonês, 4.971 trilhões de dólares (MACROTRENDS, 2020; BANCO MUNDIAL, 2020).

Parte relevante na compreensão do avanço que observamos no PIB na infra estrutura da China está nos investimentos estrangeiros diretos (IEDs) que o país recebeu no período, chegando a se posicionar como o país da região que mais recebeu investimentos nos anos 2010 (BAPTISTA, 2015, p. 4862). Como Jabour argumenta, entender a recepção de IEDs é entender o "processo de modernização a China" (JABOUR, 2010, p. 228). No entanto, a argumentação de Jabour não é a de colocar os IEDs como parte principal no desenvolvimento econômico chinês, mas sim como fazendo parte da complexa história econômica chinesa. O que fazemos aqui ao citar esse ponto é de somente evidenciar sobre como os IEDs já foram parte do processo de modernização e mudanças da China, que agora, executa seus próprios investimentos ao redor do globo.

E falar dos IEDs chineses pelo mundo, nos leva a falar da estratégia Go Global, criada em 1999, que impulsionaria esses investimentos através das multinacionais chinesas (CHINA POLICY, 2017). De acordo Zhaoxi, as motivações para a expansão de multinacionais chinesas no mundo seriam os de os de: "assegurar recursos naturais; contribuir para o ajustamento da economia chinesa; e, melhorar a competitividade internacional das empresas chinesas" (ZHAOXI, 2009, p. $31)$.

Bellabona e Spigarelli (2007, p. 94) observam esses pontos como parte da estratégia Go Global de encorajamento das multinacionais em solo internacional. Para os autores, a Go Global serviria de forma a fortalecer a presença chinesa globalmente em aspectos econômicos. Nesse caso, as multinacionais serviriam de veículos para que a China também tivesse acesso a novas tecnologias, aprimorando as próprias habilidades domésticas do país.

Nesse contexto, é válido citar a frase de Jabour que diz que, "(...) a grande empresa e o grande banco vão se tornando, com o processo histórico, o centro dos acontecimentos do mundo contemporâneo" (JABOUR, 2010, p. 247). Dessa forma, o Go Global acaba sendo parte da diplomacia chinesa enquanto um fazer "facilitador na globalização de suas empresas líderes" (Alon et al, 2014, p. 5), unindo diplomacia e economia. Como uma forma de observar os IEDs chineses por esse ângulo, podemos analisar os mesmos em relação a América Latina e a África. 
Em relação a América Latina, a presença chinesa na região apresentou considerável crescimento na última década. Em um artigo publicado em 2019, Song apresenta dados que demonstra que só naquele ano, a China tinha duas mil empresas instaladas na América Latina, pouco mais de 5\% do total de empresas chinesas fora do país. Em relação aos IEDs, os mesmos também apresentaram um pico a partir do ano de 2011, apresentando queda abrupta até 2014, quando retomou seu crescimento (SONG, 2019, p. 19).

Já em relação à África, a China apresenta grande interesse no setor de petróleo da região, interesse que faz com que o país chinês expanda seus IEDs no continente. Além da particularidade desses IEDs não estarem somente concentrados em um país, está no fato de que a China também aplica grande atenção às questões de infra estrutura na região (VALLIM, 2012). O montante do investimento chinês na infra estrutura africana chegaria a 1.5 bilhões de dólares por ano entre 2004 e 2005, alcançando um pico em 2006 onde o valor total foi de 7 bilhões de dólares (FONTE). Como Foster et al (2009, p. 12) trata, esse investimento acompanharia a aproximação comercial entre China e África, bem como a defesa dos interesses chineses em manter suas fontes de insumos energéticos tão essenciais ao seu crescimento.

Os investimentos em infraestrutura, tanto nos países da África quanto da América Latina, seriam executados com base pelas estatais - que exerceram 0 papel planejado pelo Going Global - e pelos próprios bancos de investimento chineses (NETO, 2016, p. 31). Observando os números, é possível perceber que na última década os investimentos chineses no continente africado (enquanto parte da Nova Rota da Seda) apresentaram aumento, alcançando uma média de 13.1 bilhões de dólares entre os anos de 2011 e 2015 (POON, 2018, p. 26).

Com esses dados referentes aos investimentos chineses é possível então compreender suas estratégias políticas que guiaram os rumos econômicos do país em busca de mercados, investimentos e, principalmente, de recursos primários para subsidiar seu desenvolvimento. A China entra em um ciclo onde para se sustentar internamente precisa importar recursos de outros países em cada vez maior quantidade e, consequentemente, precisa se posicionar em sua política externa em relação aos demais interesses das nações desenvolvidas. As prioridades em manter áreas de exploração de recursos na África e Eurásia, enquanto estratégia de sobrevivência econômica, se reflete na Nova Rota da Seda. Contudo, visando sustentar melhor essa percepção econômica enquanto base da política externa 
chinesa, seguimos para a próxima seção tratando da balança comercial chinesa e seus principais parceiros econômicos internacionais.

\section{Balança comercial chinesa 2000-2018}

A partir de coleta de dados do governo chinês e de outros bancos governamentais e de organismos internacionais, pudemos identificar os principais parceiros econômicos para a China, bem como os principais dados dos setores de importação chinesa dos últimos anos. Inicialmente apresentamos os dez países de quem a China mais importou entre os anos de 2000 e 2018. Dos dez países que estiveram entre os que mais importaram, somente seis estiveram dentro desse grupo em todos os anos selecionados para a análise, são eles o Japão, Coreia do Sul, Estados Unidos, Alemanha, Austrália e Malásia ${ }^{3}$ (WORLD INTEGRATED TRADE SOLUTION, 2020).

A escolha do recorte temporal seguiu a criação do Going Global, e a seleção de somente dez países se fez a fim de dar mais clareza visual sobre os dados. A seleção dos dez países foi feita de forma individual para cada ano, ou seja, em cada ano analisado, somente os países que estavam entre os dez primeiros foram contabilizados. Se um país deixou de estar entre os dez primeiros em um ano, o valor daquele ano não foi contabilizado. Um exemplo é o caso da Rússia que em 2013 e em 2015 não esteve entre os dez.

A parte mais interessante sobre os dados reunidos talvez seja em relação dos países que passaram a fazer parte dos dez maiores exportadores à China. Brasil (a partir de 2017), Arábia Saudita (começou a ser contabilizada a partir de 2007, saiu dos dez primeiros em 2014 e retornou em 2018) e a Tailândia (começou a ser contabilizada em 2001, saiu dos dez primeiros em 2001 e retornou em 2015, mas sem contabilizar 2018) traz uma diversificação global das fontes de recursos primários para a China.

É importante destacar que existem dois grupos de nações exportadoras à China: as desenvolvidas e as em desenvolvimento. Essa classificação se reflete no tipo de mercadorias importadas pela China. Enquanto a China importa bens de alto valor agregado dos países desenvolvidos, são os países em desenvolvimento (sul global) que crescem na oferta dos insumos fundamentais para o crescimento chinês, como comida, energia e minérios. No mesmo período (2000-2018), os dez maiores

3 Mais informações sobre esses dados podem ser encontrados no Gráfico 1 do material complementar. 
exportadores em desenvolvimento para a China são respectivamente: Malásia, Brasil, Arábia Saudita, Tailândia, Indonésia, África do Sul, Angola, Iran e Chile ${ }^{4}$ (WORLD INTEGRATED TRADE SOLUTION, 2020).

Com os dados dos maiores exportadores à China, temos ainda os dados por produtos importados. Quando recortamos as importações de insumos estratégicos para a base da economia chinesa (matéria prima, madeira, couros e peles), ainda que exista uma elevada taxa de importação dos bens de capital (Gráfico 1), 0 maquinário eletrônico e a matéria prima também apresentam grande aumento entre o início dos anos 2000 até o início dos anos 2010. No entanto, é possível observar uma queda no número de importações de matéria prima que ocorreu entre 2015 e 2017, demonstrando considerável recuperação já em 2018. Com isso, é possível ver um aumento de média crescente das importações da China em praticamente todos os setores nos últimos anos, demonstrando o aquecimento de sua economia e de seu PIB.

Gráfico 1 - Importação chinesa por setor estratégico à indústria 2000-2018

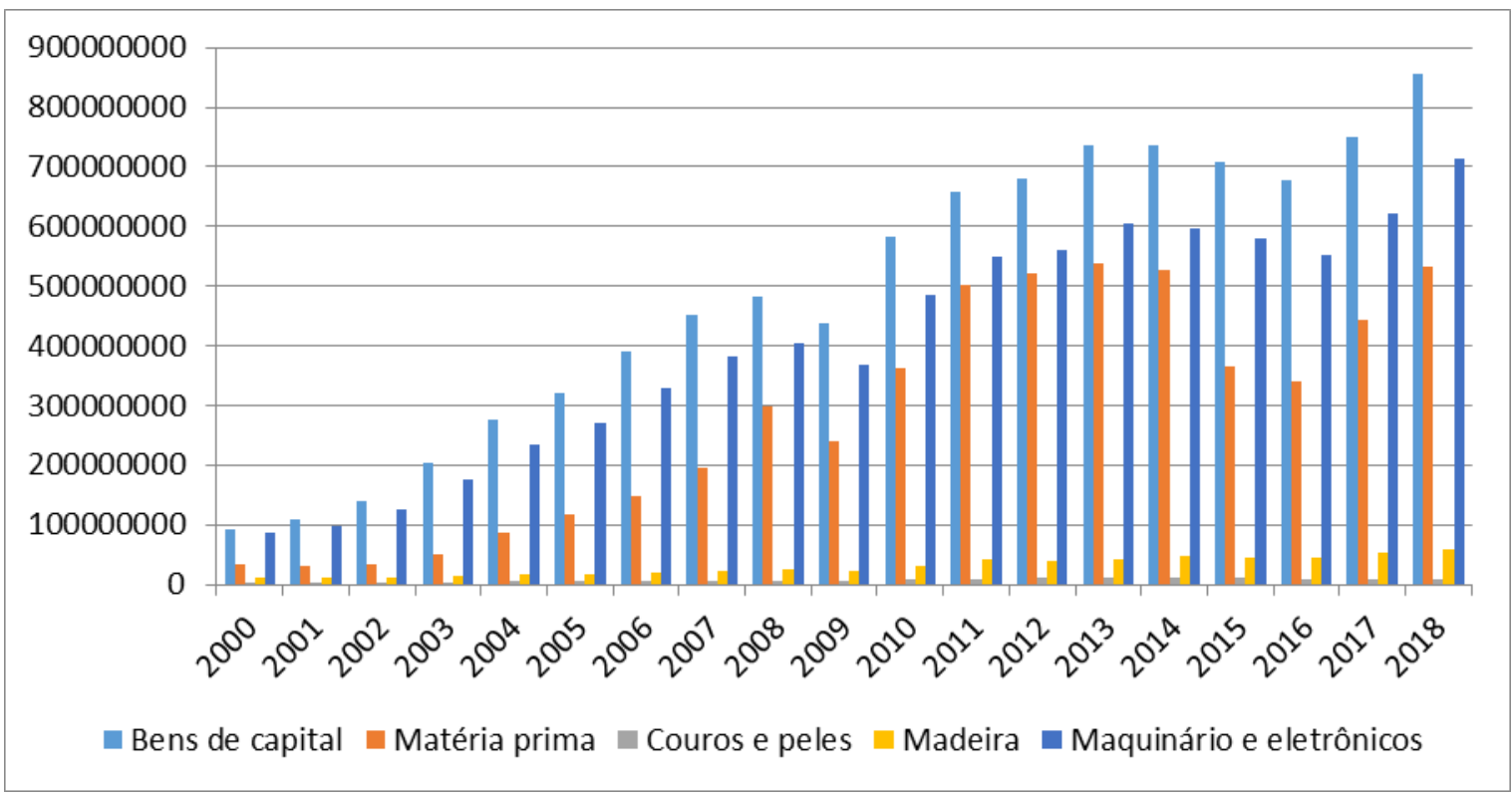

Fonte: Elaborado pelos autores, baseado em World Integrated Trade Solution, 2020. Disponível em: $<$ https://wits.worldbank.org/countrysnapshot/en/CHN> Acesso em: 15 de out. de 2020.

Já na análise mais específica da matéria prima importada, observamos que bens intermediários, combustíveis, químicos e minerais lideram respectivamente 0 subsetor entre 2000 e 2018. É possível também observar que os outros itens aqui representados, metais e plástico ou borracha, também obtiveram crescimento

\footnotetext{
${ }^{4}$ Mais informações sobre esses dados podem ser encontrados no Gráfico 2 do material complementar.
} 
considerável, sendo pedra e vidro o que se manteve com crescimento mais tímido, tendo elevação notória em 2018.

Gráfico 2 - Importação chinesa de matéria prima 2000-2018.

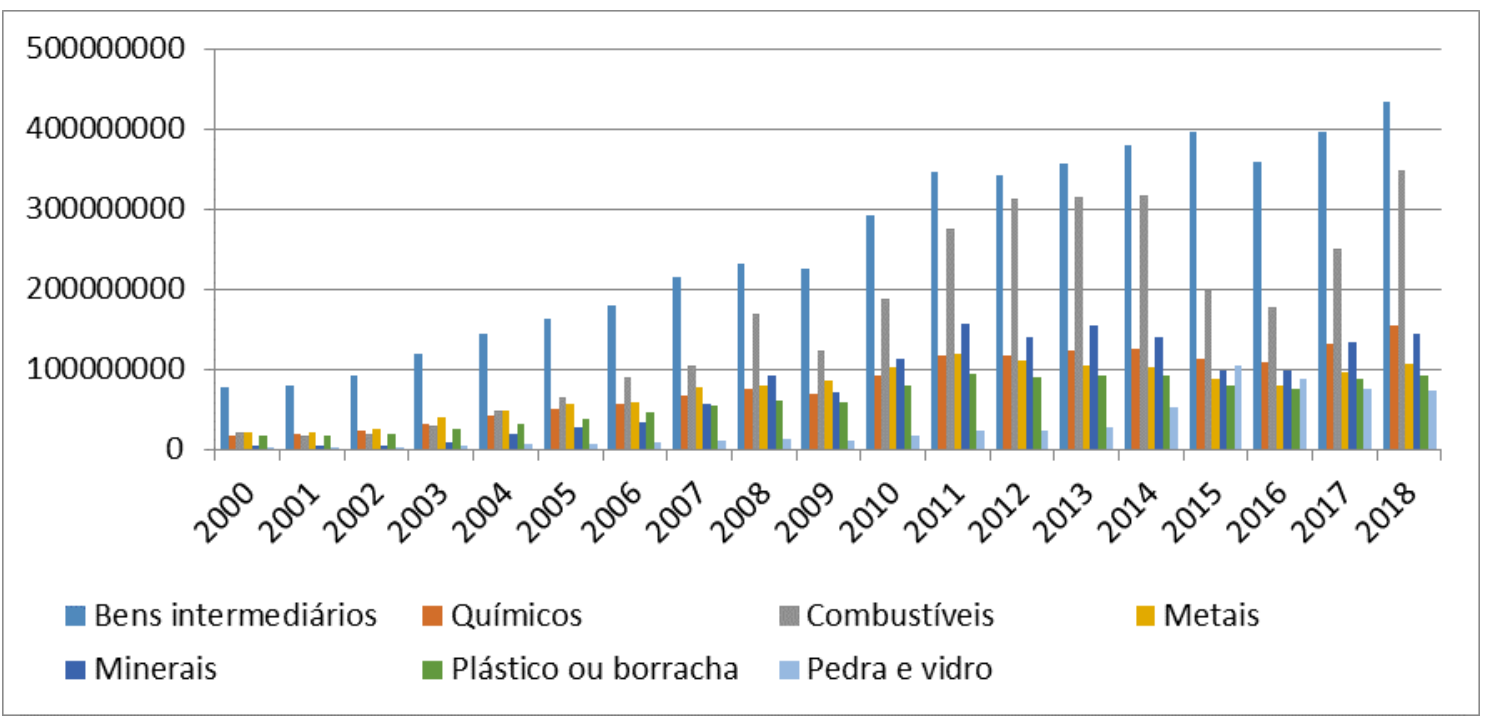

Fonte: Elaborado pelos autores, baseado em World Integrated Trade Solution, 2020. Disponível em: $<$ https://wits.worldbank.org/countrysnapshot/en/CHN> Acesso em: 15 de out. de 2020.

De forma a sintetizar mercadorias e seus exportadores à China (Tabela 1) podemos afirmar que ainda que alguns países (Estados Unidos, Coreia do Sul e Japão) estejam presentes em grande parte dos produtos analisados, percebeu-se uma tendência chinesa a diversificar suas fontes.

Tabela 1 - Maiores exportadores para a China por produto (2000-2018)

\begin{tabular}{|c|c|}
\hline PRODUTO & 2000-20018 \\
\hline Animais & $\begin{array}{c}\text { Nova Zelândia, Estados Unidos da América, Rússia, } \\
\text { Austrália, Brasil }\end{array}$ \\
\hline Bens de Capital & $\begin{array}{c}\text { Japão, Coreia do Sul, Estados Unidos da América, } \\
\text { Alemanha, Malásia }\end{array}$ \\
\hline Bens de Consumo & $\begin{array}{l}\text { Japão, Alemanha, Estados Unidos da América, Coreia do } \\
\text { Sul, Reino Unido da Grã-Bretanha }\end{array}$ \\
\hline Bens Intermediários & $\begin{array}{c}\text { Japão, Coreia do Sul, Estados Unidos da América, } \\
\text { Alemanha, Tailândia }\end{array}$ \\
\hline Calçados & Vietnã, Itália, Indonésia, Índia, Coreia do Sul \\
\hline Combustíveis & Arábia Saudita, Angola, Rússia, Iran, Oman \\
\hline Couros e Peles & $\begin{array}{l}\text { Estados Unidos da América, Itália, Coreia do Sul, Brasil, } \\
\text { Austrália }\end{array}$ \\
\hline Madeira & $\begin{array}{l}\text { Estados Unidos da América, Rússia, Canadá, Indonésia, } \\
\text { Japão }\end{array}$ \\
\hline Maquinário Eletrônico & $\begin{array}{c}\text { Japão, Estados Unidos da América, Coreia do Sul, } \\
\text { Alemanha, Hong Kong }\end{array}$ \\
\hline Matéria Prima & $\begin{array}{c}\text { Austrália, Brasil, Estados Unidos da América, Arábia } \\
\text { Saudita, Angola }\end{array}$ \\
\hline Metais & $\begin{array}{c}\text { Japão, Coreia do Sul, Chile, Estados Unidos da América, } \\
\text { Alemanha }\end{array}$ \\
\hline Minerais & Austrália, Brasil, Índia, Chile, África do Sul \\
\hline
\end{tabular}




\begin{tabular}{|c|c|}
\hline Pedras e Vidros & $\begin{array}{l}\text { Suíça, África do Sul, Japão, Estados Unidos da América, } \\
\text { Austrália }\end{array}$ \\
\hline Plástico ou Borracha & $\begin{array}{l}\text { Coréia do Sul, Japão, Tailândia, Estados Unidos da } \\
\text { América, Malásia }\end{array}$ \\
\hline Produtos alimentares & Estados Unidos da América, França, Peru, Brasil, Austrália \\
\hline Químicos & $\begin{array}{l}\text { Coréia do Sul, Japão, Estados Unidos da América, } \\
\text { Alemanha, Arábia Saudita }\end{array}$ \\
\hline Transporte & $\begin{array}{c}\text { Alemanha, Estados Unidos da América, Japão, França, } \\
\text { Reino Unido da Grã--Bretanha }\end{array}$ \\
\hline Vegetais & $\begin{array}{l}\text { Brasil, Estados Unidos da América, Argentina, Indonésia, } \\
\text { Malásia }\end{array}$ \\
\hline
\end{tabular}

Fonte: Elaborado pelos autores, baseados em World Integrated Trade Solution, 2020. Disponível em: $<$ https://wits.worldbank.org/countrysnapshot/en/CHN> Acesso em: 15 de out. de 2020.

Usando o exemplo dos bens de capital, ainda que os três países anteriormente mencionados (Estados Unidos, Coreia do Sul e Japão) tenham ficado no topo das exportações para a China, é relevante citar a Tailândia que só começou a fazer parte dos 10 maiores exportadores do produto a partir de 2003, e ainda assim, na classificação geral ficou em sexto. Essa diversificação também pode ser percebida na ótica contrária, quando vemos países como a Suíça, Reino Unido e Hong Kong que, ainda que fizeram parte de ao menos o primeiro ano de análise (2000), não continuaram a configurar entre os dez maiores exportadores de bens de capital para a China.

No caso da exportação de animais, essa diversificação é ainda maior com países como o Brasil que só passam a configurar os dez maiores exportadores a partir de 2005, e ainda assim, termina a classificação geral dos países em sexto lugar. Além disso, após a coleta dos dez maiores exportadores de cada ano, alcançamos um total de 20 países que, em um ano ou mais, passaram a configurar essa classificação, sendo esses países como os Países Baixos, Argentina, Noruega e até mesmo, a Índia. Em bens de consumo, novos países foram observados como o Turcomenistão e o Catar, e países como Reino Unido e Malásia conseguiram adentrar aos dez maiores exportadores finais do produto. Nos bens intermediários, países como Suíça e Chile passaram a configurar os dez maiores exportadores somente após 2006, mas já foi o suficiente para que ambos estivessem entre os dez na classificação final. O Brasil e Mianmar chegaram até mesmo a entrar na lista, mas não permaneceram na mesma por muito tempo.

Talvez a classificação de exportadores de combustíveis seja uma das mais interessantes de se analisar já que nela, os países que antes lideravam como a Coreia do Sul e Japão não estão entre os três primeiro. Temos então uma forte relação comercial da China com a Arábia Saudita, Angola, Rússia e Iran. Esse 
produto também apresenta alta diversificação, sendo que ao final da coleta de dados entre os dez maiores exportadores de cada ano, atingimos um total de 24 países. Em relação as exportações de couros e peles, temos entre os três maiores exportadores os Estados Unidos, Itália e Coreia do Sul, seguidos de Brasil e Austrália. A França que só passou a configurar os dez maiores exportadores a partir de 2007 acabou se tornando o sexto maior exportador na avaliação final dos números. Países como Dinamarca e Canadá, anteriormente não observados, também configuraram essa lista ao lado do Camboja, Argentina e Hong Kong.

O Canadá voltou a aparecer na lista dos maiores exportadores quando o produto analisado foi a madeira. Nesse grupo, Estados Unidos e Rússia também estavam entre os três principais exportadores, mas o Brasil, que passou a contabilizar a partir de 2003, terminou em sexto na classificação geral dos números. Nova Zelândia e Chile também apresentaram boa performance na exportação desse item. O Brasil voltou a ter destaque nas exportações de matéria prima, onde ocupou o segundo lugar. A Arábia Saudita, Angola e Iran, não tão observados entre dez principais exportadores anteriormente, também tiveram fluxos maiores de exportação para a China. Argentina, Congo, Sudão e Peru também fizeram parte da classificação final que contou com 19 países.

Nas exportações de metais, o Japão e a Coreia do Sul dividiram as primeiras colocações com o Chile. Além dele, Cazaquistão, Zâmbia e Ucrânia também fizeram parte da classificação final. Nos minerais o Brasil voltou a ocupar uma das primeiras posições entre os exportadores ao lado da Austrália e índia. A África do Sul, Peru e Indonésia também demonstraram fortes laços na exportação desses produtos para a China. Em relação aos produtos alimentares, é interessante notar que ainda que os Estados Unidos ocupam o topo das exportações para a China, países como a França, Peru e Brasil estão logo atrás. Esse também é um dos produtos com maior diversificação de exportadores, alcançando um total de 24 países que, em um ano ou mais, estiveram entre os 10 maiores exportadores de alimentos para a China.

Citando novamente o Brasil, o país ocupou o primeiro lugar na exportação de vegetais para a China, seguido dos Estados Unidos e Argentina. Nesse item, a Índia e Filipinas chegaram a ocupar uma posição entre os dez maiores exportadores em um ano ou mais, mas não adentraram como maiores exportadores na avaliação geral. É interessante notar a presença de países como o Uruguai e a Ucrânia entre os maiores exportadores. 
Contudo, dando ênfase aos países que se encontram na Nova Rota da Seda, ou estão em algum tipo de acordo com o governo chinês sob o nome da Nova Rota, analisando a partir da tabela acima apresentada, observamos a presença da Alemanha, Rússia, Malásia, França, Índia, Iran, África do Sul, Oman, Tailândia, Indonésia, Arábia Saudita, Angola, Suíça, Hong Kong. A quantidade de países não é pouca, no entanto, quando analisamos os três maiores exportadores de acordo com a quantidade de diferentes produtos que exportam para a China, os mesmos ainda se mantém como sendo os Estados Unidos, Japão e Coréia do Sul. Seguidos da Alemanha, único país parte da Rota da Seda a configurar o topo da lista apresentada.

\section{O realismo ofensivo e sua possível contribuição para o caso chinês}

Se os Estados tomam medidas racionais em suas políticas externas e se a segurança é seu principal objetivo, logo um Estado fará escolhas racionais para alcançar maior grau de segurança. Essa busca por segurança, diferentemente do que os realistas defensivos propõem, só poderia ser alcançada quando os recursos de poder de uma nação superar os das demais. Essas concepções são conhecidas do realismo ofensivo de John Mearsheimer (2001). Assim como muitos realistas, Mearsheimer defende a possibilidade de observamos o comportamento de um Estado a partir de escolhas racionais pelos maiores ganhos relativos e, às vezes, os absolutos.

Enquanto que os realistas defensivos propõem um comportamento que reflete a estrutura de equilíbrio de poderes no sistema internacional, como nos últimos trabalhos de Kenneth Waltz, Mearsheimer e outros realistas cunhados de ofensivos defenderiam que apenas quando um Estado for mais forte que seus concorrentes é que poderá ter um pouco mais de tranquilidade em sua agenda de segurança, do contrário, as disputas serão correntes e advindas das inseguranças e incertezas no cenário internacional. Isso significaria que o equilíbrio de poder entre um conjunto de potências (multipolar ou bipolar) seria marcado sempre por corridas ao poder - e não necessariamente traria uma ordem conformada por todos.

Para John Mearsheimer (2001) as grandes potências seriam sempre forças revisionistas na eterna busca da maximização de seu poder. Isso significa que, potências em ascensão ou que já se encontram historicamente no cerne dos recursos mundiais irão priorizar a ultrapassagem na corrida pelo poder e sua ameaça aos demais (Buck-Passing) ao invés de se contentarem com as estratégias 
de equilíbrio de poder no status quo (Balancing) - essa última defendida pelos realistas defensivos, como Waltz. Apenas com maiores somas dos recursos de poder é que as ameaças seriam superadas e a segurança, de fato, conquistada.

Por isso, quando observamos os dados comerciais chineses versus suas práticas internacionais podemos perceber uma estratégia de captação de recursos e controle de estruturas logísticas para o seu crescimento econômico. As estratégias da Nova Rota da Seda se alinham com obras de infraestrutura, criação ou modernização de portos e abertura de empresas chinesas em áreas estratégicas para o escoamento das mercadorias dos principais exportadores em desenvolvimento aqui identificados nas importações chinesas.

Até aqui poderíamos entender como apenas investimentos econômicos para agilizar o comércio exterior. Mas devemos relembrar as análises históricas de Paul Kennedy (1987) ao associar o crescimento de uma potência a partir do equilíbrio entre poder bélico e desenvolvimento econômico. Os recursos que alimentam uma economia industrializada seriam os mesmos que alimentariam a indústria bélica. Também poderíamos reinterpretar o conceito de espaço vital de Friedrich Ratzel sobre o ciclo de vida de um Estado que, para crescer, buscaria recursos para além de suas fronteiras originais $(1895 ; 2016)$. Ainda que a China não busque uma expansão oitocentista ou novecentista anexando territórios pelo mundo, ela auxilia suas empresas a assumirem o controle da exploração e escoamento dos recursos de nações em desenvolvimento ao longo da Nova Rota da Seda com sua política Go Global: para crescer seria preciso consumir.

Essa busca seria o conceito de 'maximização do poder' apresentado por Mearsheimer (2001). Contudo, ao aplicar o realismo ofensivo não se busca dizer que a China é uma potência hegemônica ou que superará em breve os EUA, mas que, ao menos, segue um caminho de busca por poder e recursos mundo a fora. Em relação ao domínio tecnológico a China disputaria espaço com outras potências, como EUA que a superaria. Todavia, os dados chineses em sua corrida armamentista impressionam. Nas últimas décadas a China intensificou seu crescimento bélico, especialmente em tecnologias marítima e aeroespaciais, como aponta os estudos de Arthur Coelho Dornelles Jr. (2014, p. 162):

[...] o esforço de balanceamento no Leste Asiático levou à configuração de uma balança regional bipolar desequilibrada em favor da China, em que a RPC [República Popular da China] é preponderante na dimensão terrestre, e atualmente se apresenta como um adversário à altura dos Estados Unidos na esfera naval, pois o ELP [Exército de Libertação do Povo] é capaz de travar uma guerra marítima (convencional) contra as forças estadunidenses no Leste Asiático, com grandes chances de degradar seriamente a 
capacidade de combate dos Estados Unidos na região e forçar o encerramento das hostilidades, mantendo seus interesses intactos.

O lançamento em 2007 de seu primeiro míssil antissatélite incomodou governos como o do Japão, Coreia do Sul, Canadá e EUA. Hoje, em 2020, a China termina de lançar seu último satélite do Sistema de Navegação Beidou que libertaria a China de sistemas de navegação e controle estadunidense (GPS), europeu (Galileo) e russo (Glonass). O próprio contingente humano chinês é hoje a maior força armada nacional do planeta.

Já em relação ao cenário de status quo entre as potências atuais esse não seria estável - talvez nem possível de existir, como aponta Mearsheimer (2001) em sua ideia principal: uma potência mundial quando tiver a oportunidade de assumir uma posição hegemônica não irá perder essa chance, ainda que precise assumir uma postura agressiva em relação às demais. Um status quo não poderia existir por nenhum Estado confiar entre si, bem como gerar corridas armamentistas e econômicas de maximização do poder e superação - conflito - entre si. Talvez esses conflitos não ocorram diretamente em guerras nos territórios respectivos das potências em competição, mas geram sim conflitos em políticas comerciais, intervenções e interferências em outras partes do mundo de interesse mútuo. A escalada de um conflito econômico para um bélico pode demorar ou até não existir, mas não poderíamos dizer que uma guerra é feita apenas de trocas de tiros e invasões entre as partes - caso contrário, a Guerra Fria não teria existido enquanto tal.

É válida a inserção de um outro debate nessa seção, o debate sobre qual o discurso que a China alimenta durante os anos que acompanharam sua ascensão internacional em campo doméstico e diplomático. Em um livro publicado 2005 reunindo as falas do pensador chinês, Zheng Bujian, um termo se repete 202 vezes (incluindo no título) no decorrer de suas 101 páginas; "ascensão pacífica”. Um dos discursos defendidos por Bujian é o de que a busca por hegemonia não trás sucesso a nação alguma, e é em vista disso que a China exerceria sua ascensão mundial através de práticas pacíficas de cooperação. Em um dos trechos do livro, lê-se,(...) pela inabalável aderência ao caminho de desenvolvimento pela ascensão pacífica, nós buscamos nos transformar em um país socialista moderno que é próspero, democrático, e culturalmente avançado(... ${ }^{5}$ (BIJIAN, 2005, p. 7).

\footnotetext{
${ }^{5}$ (...) by unswerving adherence to a development path of peaceful rise, we seek to become a modern socialist country that is prosperous, democratic, and culturally advanced (...)
} 
A inserção do trecho acima, assim como a escolha da adesão do termo "ascensão pacífica" nesse artigo não busca atribuir a China o caráter físico de nação pacifista que iria em direção contrária as grandes hegemonias, ou até mesmo, como forma de debater a fala de Mearsheimer. A inclusão dessa abordagem se faz de forma a expressar a visão chinesa sobre si mesma, e, mais importante que isso, o discurso que permeia as ações da China como um país relevante e importante nas relações internacionais contemporâneas.

O cenário internacional atual, de inseguranças políticas e competitividade comercial, criam tensões e conflitos que podemos ver hoje abertamente nos discursos dos governos de Donald Trump e o chinês em diversos setores, desde insumos minerais, passando pela centralização da produção terceirizada das indústrias até exercícios militares e demonstração de força naval e espacial. Mas enquanto foco na Nova Rota da Seda os dados comerciais aqui levantados apontam para os dois grupos de países que mais exportam para a China: os desenvolvidos e os em desenvolvimento. No primeiro grupo existem parcerias e conflitos políticos, como as políticas comerciais protecionistas dos EUA ou as ameaças de retirada industrial japonesa da China. Já no segundo grupo, dos em desenvolvimento, a China investe na infraestrutura e na logística de exploração de recursos e insumos para assegurar suas fontes de crescimento econômico e, consequentemente, bélico e de segurança.

\section{A Nova Rota da Seda e a estratégia política chinesa}

Considerando os gráficos, assim como a tabela acima apresentados, algumas considerações podem ser retiradas de um ponto de vista mais quantitativo. Em primeiro lugar, tratando dos maiores exportadores para a China, vemos a predominância do Japão, Coreia do Sul e Estados Unidos. O Japão apresentou um pico nas exportações para a China no ano de 2010, seguido dos Estados Unidos que teve pico em 2014 e a Coreia do Sul, com um pico em 2018. Seguido desses três países, temos a Alemanha, Austrália e o Brasil, sendo que o último apresentou crescimento considerável a partir de 2018, e a Alemanha é a única a configurar esse grupo que também faz parte da Nova Rota da Seda.

Os três países que estiveram no topo das exportações para a China também estiveram entre os maiores exportadores de insumos. Ou seja, temos novamente o fortalecimento das relações comerciais entre China e Estados Unidos, Japão e 
Coréia do Sul. A tendência comercial nas relações entre a China e esses três países também apresenta conexão com as tendências dos IEDs chineses, como podemos observar nos dados apresentados pelo The China Global Investment Tracker (CGIT, 2020). Entre 2005 e 2020, os investimentos para os Estados Unidos, Japão e Coreia do Sul foram, respectivamente de 187.8 bilhões de dólares, 10.63 bilhões de dólares e 12.58 bilhões de dólares. Vemos uma concentração grande dos investimentos chineses em território americano, fazendo com que os investimentos tanto no Japão quanto Coreia do Sul pareçam quase insignificantes em comparação.

Em relação aos outros insumos que estiveram entre os mais exportados para a China, temos os maquinários e eletrônicos, onde os países que mais fazem parte das exportações voltam a ser os Estados Unidos, Coreia do Sul e Japão, dessa vez também havendo a adição da Alemanha e Hong Kong. No caso da Alemanha, vale apresentar as informações sobre os investimentos chineses no país que, entre 2005 e 2020, chegaram a 47.58 bilhões de dólares (CGIT, 2020). No entanto, outros dois insumos que tiveram destaque nos gráficos apresentados e que devem ser citados principalmente devido a sua diversidade de fontes, são a matéria prima e os minerais.

Para ambos, o Brasil é apresentando como um dos maiores exportadores. Em relação à matéria prima, além do Brasil, países como a Angola e Arábia Saudita (países que farão parte da Nova Rota) também configuram a lista de maiores exportadores para a China. Configurando assim, a relevância de países membros do sul-global na exportação de um dos principais insumos para a China. Em relação aos minerais, além do Brasil, a África do Sul, Índia e Chile também marcam presença confirmado a aproximação de laços chineses com países membros da região sul. Por último, tratando diretamente dos itens mais exportados, os combustíveis apresentarem considerável crescimento até o ano de 2015, havendo retomada em 2017. Em relação a esse insumo, vemos a presença de diferentes nações como sendo as exportadoras, sendo essas a Arábia Saudita, Angola, Iran e Oman, representando os países que estão em acordo com o projeto da rota.

Revisando o total de IEDs chineses entre esses países citados no último parágrafo, no intervalo entre 2005 e 2020, observamos os números: Brasil, 68.56 bilhões de dólares; África do Sul, 14.15 bilhões de dólares; Angola, 24.42 bilhões de dólares; Arábia Saudita, 38.54 bilhões de dólares; Índia, 34.7 bilhões de dólares; Chile, 11.67 bilhões de dólares; Iran, 26.56 bilhões de dólares e; Oman, 5.81 bilhões de dólares. É válida também a adição dos valores para a Rússia e Austrália que 
também configuraram entre os países que mais exportaram, respectivamente, combustíveis e matéria prima, sendo os valores totais de investimentos 54.54 bilhões de dólares para a Rússia e, 116.19 bilhões de dólares (CGIT, 2020).

É crescente a presença de empresas chinesas na exploração de recursos ligados ao seu desenvolvimento. A compra da mineradora Sul Americana Metais pela chinesa Honbridge Holdings, em 2010, implementa seus projetos de exploração de recursos minerais Grão Mogol em Minas Gerais (Brasil). Junto à Arábia Saudita, em 2019 o príncipe herdeiro, Mohammed bin Salman, visitou Pequi, o que culminou com projetos de investimentos mútuos, como na consolidação do conglomerado de exploração e refinaria de petróleo Huajin Aramco Petrochemical. A Arábia Saudita forneceria até $70 \%$ do petróleo para a refinaria a ser construída na China, em uma junção da empresa saudita Aramco (petrolífera) com as chinesas Norinco (produção de motorizados) e Panjin Sincen (construtora).

Ainda que EUA, Japão e Coreia do Sul sejam os principais parceiros em exportações para a China, os dados do sul global apontam por uma diversificação crescente da China em seu mercado de importação. Os dados de crescimento diversificado das importações chinesas nos direcionam para problematizar a presença crescente das nações da Nova Rota da Seda. Isso pode nos levar a uma percepção da Nova Rota da Seda como uma forma de diminuir a dependência chinesa das três nações desenvolvidas.

Vale destacar ainda que essa expansão chinesa pelo mundo não é algo pacífico e resultado de consenso entre todas as partes. Conflitos e protestos ocorrem por parte de empresários locais e de movimentos mais nacionalistas. Um exemplo é da própria Índia que, em 2020, por consequência de conflitos armados nas fronteiras. Com a morte de aproximadamente vinte soldados indianos por forças chinesas, movimentos de boicotes ocorreram em todo o país aos produtos e acordos com a China. Além disso, é possível ver diversas iniciativas de países questionando as práticas comerciais chinesas nos painéis de arbitragem da OMC. Dessa forma, a maximização de recursos pela China esbarra em conflitos políticos e comerciais que exigem maior desempenho de sua política externa.

Como podemos observar, a direção de IEDs chineses não parece estar tão conectado com seu fluxo de importação já que tanto o Japão quanto a Coreia do Sul, países que estiveram no topo entre os exportadores para a China, apresentaram valores de IEDs recebidos próximos aos da África do Sul e Chile. Isso pode nos levar então para outros questionamentos: o baixo IED chinês nesses 
países, Japão e Coreia do Sul, estaria conectado com a não necessidade de desenvolvimento de infra estrutura na região? O fato de países como o Brasil e Índia apresentarem valores consideráveis na recepção de IEDs os colocariam em posição de destaque na visão chinesa em e expandir por terras mais receptíveis que ofertassem minerais e demais matéria prima?

Para ambas perguntas o presente trabalho poderia apenas apontar possibilidades: aos países de baixa infraestrutura com abundância de recursos atrairia a China e seus IEDs com maior poder de barganha comercial do que em países desenvolvidos, com baixa receptividade aos IEDs chineses. O que se pode afirmar a partir dos dados é que a China: I. Está diversificando seus exportadores de recursos e matéria prima; II. O que diminuiria sua dependência aos mercados de países com grande poder de embate, como os EUA; III. Ao mesmo tempo que possibilita a maximização de recursos econômicos e; IV. Consequentemente aumentaria a maximização de recursos de poder; V. questionando a posição das demais nações desenvolvidas e criando conflitos de interesses, como visto nas políticas comerciais de Donald Trump à China nos últimos anos.

Dessa forma, a Nova Rota da Seda parte para ganhos comerciais e econômicos que resultariam em ganhos políticos e de segurança ao desenvolvimento interno chinês. Da comida às bases industriais e logística, todos os setores tidos como essenciais pelo governo chinês são contemplados em seu projeto. Ainda que a China não se coloque como uma nação de significativo crescimento, candidata à hegemonia, é possível ver os preceitos de Mearsheimer (2001) sobre como o Estado utiliza de suas ferramentas para garantir o controle de recursos de poder ao redor do mundo e, consequentemente, como a Rota da Seda se coloca como questionadora junto às demais nações desenvolvidas.

\section{Considerações Finais}

Tendo início como uma forma de encontrar os gargalos econômicos a serem superados pela China através da criação da Nova Rota da Seda, o presente artigo conseguiu identificar mais do que apenas aspectos puramente econômicos na relação entre o dragão chinês e seus principais exportadores. Um dos principais ponto descobertos durante a coleta e análise dos dados apresenta uma China que passou a diversificar ainda mais as fontes de suas exportações, principalmente após 2010. Essa diversificação não retira o protagonismo de países como os Estados 
Unidos, Japão e Coreia do Sul na balança comercial chinesa, mas coloca a China como protagonista de muitas outras políticas externas de nações do sul global.

Como interpretarmos a busca por novas fontes que a China parece executar? Considerando as tensões geopolíticas que a China vem enfrentando há anos com o Japão e Coreia do Sul, e até mesmo as mais recentes tensões com os Estados Unidos, a busca por diversificação por investimentos se torna uma estratégia menos nebulosa e de maior facilidade de compreensão. Considerando o tamanho de sua população e a ambição chinesa por desenvolvimento, não é surpresa sua busca por segurança quando o assunto se faz em relação aos seus parceiros comerciais - e fontes materiais do seu crescimento econômico e político. Eventos como a Grande Fome vivenciada pela China, e sua constante luta no desenvolvimento da indústria interna, servem de contextualização para o comportamento chinês atual.

A diversificação das exportações chinesas também parece seguir o discurso chinês que se fez presente dentro dos BRICS, por exemplo, ao se observar como um país que faz parte do grupo de nações em desenvolvimento e se posicionar como uma voz contrária à hegemonia e dominação muitas vezes observada. Isso, em um todo, acompanha o discurso de ascensão pacífica chinesa. Mas como tratar a ascensão pacífica junto às grandes potências quando estamos falando de comércio e crescimento econômico?

Nesse ponto, assumir as estratégias de diversificação de parcerias, relativa transparência em seu plano da Nova Rota da Seda e discursos de não-conflito pode vir ajudando o governo chinês. Contudo, os conflitos locais surgem no sul global e junto às políticas comerciais dos EUA, Japão e outras nações desenvolvidas, mesmo que haja um discurso chinês de ascensão pacífica. Adotar e buscar construir uma identidade pacífica e de cooperação acompanha o discurso chinês contrário as técnicas de dominação hegemônicas que colonizavam e exploravam o sul global no século passado. Mas seria a China uma candidata à potência revisionista das relações internacionais? Segundo aplicação dos conceitos de maximização e ausência de status quo de Mearshemier (2001), a China estaria apenas seguindo o caminho de todas as outras nações: maximizando seus recursos de crescimento para garantir poder e segurança e, no dia em que surgir a oportunidade, mesmo com discurso pacifista, a China aceitará seu lugar mais elevado na estrutura internacional. 
Com isso, não estaríamos aqui negando a fala de Mearsheimer sobre a hegemonia ser uma questão de oportunidade, o que pode ocorrer aos que apenas levam em consideração o discurso oficial chinês pacifista. Não estamos anulando a possível busca por poder e influência chinesa que se faz de forma a explorar os caminhos comerciais e utilizar seus IEDs como forma de pavimentar suas relações com as nações que detém recursos naturais de seu interesse. Pelo contrário, suas práticas mostram a maximização crescente de recursos e posicionamentos de tensão com as demais potências. Mas é preciso ressaltar a discussão sobre como falar de hegemonia ao tratar de uma nação não ocidental.

Assim como Edward Said tratou em seu livro "Orientalismo" (1978), reconhecemos que muitas vezes o pesquisador ocidental olha para o Oriente como o lugar do exótico, o estranho. Ainda que Said não estivesse tratando sobre a China, sua crítica aqui se faz relevante ao tentarmos encaixar uma nação como a China nos estereótipos e nomenclaturas que nasceram e foram praticadas no Ocidente. Não somente cometemos um equívoco como empobrecemos a análise e ignoramos aspectos culturais e filosóficos da nação chinesa se buscarmos entender o discurso sem observar suas práticas.

Quando analisamos o discurso de ascensão pacífica chinesa, não observamos uma congruência com a prática na vida real. Sob o nosso olhar ocidental e acostumado com as práticas hegemônicas ocidentalizadas, podemos observar traços que demonstram uma preparação para uma guinada chinesa rumo a uma possível liderança para além de sua região. Com isso, adotamos a fala de Mearsheimer e nos questionamos: Seria a Nova Rota da Seda uma forma de alcançar esse patamar? Enquanto análise do resultado de pesquisa podemos dizer que a Nova Roda da Seda se enquadraria em práticas de maximização de recursos de poder para garantir a segurança chinesa.

\section{REFERÊNCIAS}

ALON, Ilan; WANG, Hua; SHEN, Jun; ZHANG, Wenzian. Chinese state-owned enterprises go global. Journal of Business Strategy, vol. 35, n. 6, p. 3-18, 2014.

BAPTISTA, Thiago J. Os Investimentos da República Popular da China no Mundo Globalizado: Novas Territorialidades no Processo de Reestruturação Territorial Fluminense. XI Encontro Nacional da ANPEGE, 2015.

BARNETT, Doak; CLOUGH, Ralph. Modernizing China: Post-mao Reform And Development. Westview Press; Edição: 1, 1986. 
BELLABONA, Paola; SPIGARELLI, Francesca. Moving from Open Door to Go Globa: China goes on the world stage. Int. J. Chinese Culture and Management, vol. 1, n. 1, 2007.

BIJIAN, Zheng. China's Peaceful Rise: Speeches of Zheng Bijian 1997-2005. The Brookings Institution, 2005.

CHEN, Sheying. Economic Reform and Social Change in China: Past, Present, and Future of the Economic State. International Journal of Politics, Culture and Society, vol. 15, n. 4, 2002.

CHINA GLOBAL INVESTMENT TRACKER, 2020. Disponível em: < https://www.aei.org/china-global-investment-tracker/> Acesso em: 14 de agosto de 2020.

CHINA POLICY. China Going Global: between ambition and capacity. 2007.

COLAKOĞLU, Selçuk. China's Belt and Road Initiative and Turkey's Middle Corridor: A Question of Compatibility. Middle East Institute, 2019. Disponível em: < $<$ https://www.mei.edu/publications/chinas-belt-and-road-initiative-and-turkeys-middlecorridor-question-compatibility> Acesso em: 15 de agosto de 2020.

DORNELLES JR., Arthur Coelho. A modernização militar da China e a distribuição de poder no Leste Asiático. Contexto Internacional, vol. 36, n. 1, 2014, p. 145-170. Disponível em https://www.scielo.br/pdf/cint/v36n1/a05v36n1.pdf . Acesso em 19/08/2020.

FAIRBANK, John K.; GOLDMAN, Merle. China: A New History. The Belknap Press of Harvard University Press, Londres, $2^{\mathrm{a}}$ ed, 2006.

FOSTER, Vivien; BUTTERFIELD, William; CHEN, Chuan; PUSHAK, Nataliya. Building Bridges: China's Growing Role as Infrastructure Financier for Sub-Saharan Africa. Trends and Policy Options, n. 5, 2009.

SONG, Xiaoyu. Regulations of Chinese OFDI: General Trends in Latin America and the Caribbean (2000-2018) In PETERS, Enrique D. China's Foreign Direct Investment in Latin America and the Caribbean: Conditions and Challenges, 2019.

RATZEL, Friedrich. History of Mankind (1895). Hansebooks, 2016.

KENNEDY, Paul. The rise and fall of the great powers. New York: Random House, 1987.

JABOUR, Elias Marco K. Projeto Nacional, Desenvolvimento e Socialismo de Mercado na China de Hoje. Universidade de São Paulo (Tese de doutorado em Geografia Humana), 2010.

MACROTRENDS. China GDP 1960-2020. Disponível em: $<$ https://www.macrotrends.net/countries/CHN/china/gdp-gross-domestic-product> Acesso em: 25 de agosto de 2020.

MEARSHEIMER, John. The Tragedy of Great Power Politics. Nova York: Norton, 2001.

NONNENBERG, Marcelo José B. China: Estabilidade e crescimento econômico. Revista de Economia Política, vol. 30, n. 2, p. 201-218, 2010.

POON, Daniel. China's Overseas Development Finance: Policy Tools and Mechanisms. In China: Direções Globais de Investimentos. Conselho Empresarial Brasil-China; ApexBrasil, 2018. 
PUTTERMAN, Louis. Dualism and Reform in China. University of Chicago, 1992.

SACHS, Jeffrey; WOO, Wing T.; FISCHER, Stanley; HUGHES, Gordon. Structural Factors in te Economic Reforms of China, Eastern Europe, and the Former Soviet Union. Economic Policy, vol. 9, n. 18, p. 101-145, 1994.

THE PEOPLE'S REPUBLIC OF CHINA. Full text: Action plan on the Belt and Road Initiative. Disponível em: <http://english.www.gov.cn/archive/publications/2015/03/30/content 281475080249035.htm > Acesso em: 15 de agosto de 2020.

THE PEOPLE'S REPUBLIC OF CHINAb. China's Belt and Road plan 'open' to all nations. Disponível em:

$<$ http://english.www.gov.cn/news/top news/2015/04/18/content 281475091262006.htm>

Acesso em: 15 de agosto de 2020.

VALLIM, Roberto B. Investimentos Externos Diretos da China no Resto do Mundo. Universidade Federal do Rio de Janeiro (Monografia em Economia), 2012.

WORLD TRADE SOLUTION. China. 2020. Disponível em: < https://wits.worldbank.org/countrysnapshot/en/CHN> Acesso em: 15 de out. de 2020.

XINHUA. China's Belt and Road Initiative benefits world: experts. The People's Republic of China, 2015.2 Disponível em: <http://english.www.gov.cn/news/top news/2015/10/15/content 281475212268936.htm>

Acesso em: 15 de outubro de 2020.

ZHAO, X. B.; ZHANG, L. Decentralization Reforms and Regionalism in China: A Review. International Regional Science Review, 22, n. 3, p. 251-281, 1999.

\section{NOTAS DE AUTOR}

\section{CONTRIBUIÇÃO DE AUTORIA}

Bruna Leal Barcellos - Concepção e elaboração do manuscrito; Coleta de dados; Análise de dados; Participação ativa da discussão dos resultados; Revisão e aprovação da versão final do trabalho.

Leonardo Mèrcher - Concepção e elaboração do manuscrito; Coleta de dados; Análise de dados; Participação ativa da discussão dos resultados; Revisão e aprovação da versão final do trabalho.

\section{FINANCIAMENTO}

Coordenação de Aperfeiçoamento de Pessoal de Nível Superior (CAPES)

CONSENTIMENTO DE USO DE IMAGEM

Não se aplica.

\section{APROVAÇÃO DE COMITÊ DE ÉTICA EM PESQUISA}

Não se aplica.

CONFLITO DE INTERESSES

Não se aplica.

\section{LICENÇA DE USO}

Este artigo está licenciado sob a Licença Creative Commons CC-BY. Com essa licença você pode compartilhar, adaptar, criar para qualquer fim, desde que atribua a autoria da obra.

\section{HISTÓRICO}

Recebido em: 25-08-2020

Aprovado em: 28-09-2020 